\title{
Editorial: Re-embedding Nutrition in Society, Nature and Politics
}

\author{
STEFANO PRATO AND \\ NICOLA BULLARD
}

This issue of Development was prepared in the lead-up to the Second International Conference on Nutrition (ICN2), an intergovernmental conference organized by the Food and Agricultural Organization (FAO) and the World Health Organization (WHO) to address malnutrition in all its forms. Held in Rome, Italy, on 19-21 November 2014, the conference took place 22 years after the first ICN. While the articles in this issue were completed immediately before ICN2, this editorial is written in its aftermath and therefore reflects on the outcomes of the process.

Nutrition is considered a technical matter by most and the conference preparations attempted to de-root nutrition from its intimate relations with the nature of food systems as well as its broader social, economic and political determinants. In contrast, the articles in this issue highlight that nutrition is a profoundly political issue not only for its deep implications on people's rights, livelihoods and health, but also because of the consequences that choosing among alternative paths to nutrition may have on the nature and pattern of globalization. It is indeed one of the underlying framing issues of our times and the critical battlefield of the struggle between the hegemonic form of economic and cultural globalization and the alternatives offered by the solidarity and social economy as well as the philosophy and practice of Buen Vivir. The aspiration for adequate nutrition demarcates a critical crossroads: on one side, the emerging global food system that promotes unhealthy and unsustainable diets based on ultra-processed foods and beverages, and increasingly dispossesses small-scale food producers and their communities of resources, opportunities and dignity. On the other, a democratic and culturally diverse polyphony of local vibrant food systems based on food sovereignty, women's empowerment, biodiversity, deep environmental foundations, agro-ecological principles and economic pluralism.

The forces at play are powerful. For the agro-industrial and pharmaceutical complex, malnutrition is indeed good business and so is the increasing incidence of diet-related non-communicable diseases. Chronic illness with several consequential secondary diseases are goldmines for pharmaceutical companies, exactly as nutritional deficits offer ample market opportunities for supplementation, food fortification and genetic 
modification of crops. Uninformed and often not well-thought through consumer choices tend to consolidate the pervasive influence of these types of business on people's lives.

As an introduction to the articles in this journal, let us attempt to shed a different light on some of these issues and offer a five-step journey to understanding the deeply political nature of the challenge of malnutrition in all its forms.

\section{Demystifying the neo-Malthusian narrative}

As a first step, it is necessary to demystify the current neo-Malthusian narrative. We often hear about the challenge of 'feeding a growing planet' in terms that evoke the urgency of increasing productivity and production, access unused land and promote the adoption of new technologies that can increase the nutritional content of crops. In this context, it is not rare to encounter representatives of transnational corporations portraying with significant pathos their plans to step-up to their responsibility in feeding a growing global population. This narrative is increasingly combined with highlights of nutritional deficiencies and the need for supplementation and food fortification. In the name of fighting malnutrition, marketing at all latitudes proposes vitamin pills and mineral supplements as well as food and beverages with added nutritional value, posting deeply in our minds the idea that product-based technological solutions are what we need to stay healthy. As an experienced magician would do, the advertising bombardment ensures that we do not focus on the root causes of our increasing unhealthy diets.

We should invite these corporations to step back. When we debunk the myths behind the current narrative, we discover a world dramatically different from what is depicted, one where the agro-industrial complex is a significant part of the problem rather than the solution.

First, there is no shortage of food. Global food loss and waste account for approximately one third of the edible parts of food produced for human consumption and they derive largely from the agro-industrial model of production itself. Second, 130 many emerging nutritional deficiencies are the result of unhealthy diets, which feature decreased intake of fresh fruit and vegetables, and increased consumption of ultra-processed food high in salt, sugar and saturated fats. Furthermore, adequate nutrition is endangered by the increasing loss of biodiversity, which finds in intensive agriculture one of its greatest enemies. Once again, the agri-food business complex offers its product supplementation solutions to problems it has itself generated. Third, the tension is not really between population growth and food production but rather between the latter and its environmental footprint in terms of unsustainable use of resources (i.e., water), environmental damage (i.e., chemical contaminations) and contribution to climate change (i.e., greenhouse gas emissions). Once again, the environmental unfriendliness of agro-industrial production is at the core of the problem.

\section{Food sovereignty charts an alternative path to nutrition}

Small-scale and family food producers feed 70 percent of the world population and are the main investors in agriculture. Despite this evidence, international agreements and governmental policies continue to push for an agri-business model that increases the control of the food system by multinational companies at the expense of peasants and small-scale food producers. Emerging global value chains that relegate primary producers to powerless conditions of dependency with uneven terms of trade, corporate grabbing of land, oceans, lakes and aquatic resources, infrastructural developments that promote import/export rather than domestic market development and lack of investment in local markets and value chains, have all contributed to displacement and impoverishment of small-scale producers all over the world. This is clearly articulated by the Statement by Social Movements to ICN2. ${ }^{1}$

The weakening of local food systems has profound implications on the nutritional status of both rural and urban populations as it is closely connected with the decrease in diversity and quality of diets. Food sovereignty is therefore a fundamental pre-condition for food and nutrition security and the founding pillar to guarantee the human right 


\section{Prato and Bullard: Editorial}

to adequate food and nutrition, as clearly stated in the Declaration of Nyéléni: ${ }^{2}$

Food sovereignty is the right of peoples to healthy and culturally appropriate food produced through ecologically sound and sustainable methods, and their right to define their own food and agriculture systems. It puts the aspirations and needs of those who produce, distribute and consume food at the heart of food systems and policies rather than the demands of markets and corporations. It defends the interests and inclusion of the next generation. It offers a strategy to resist and dismantle the current corporate trade and food regime, and directions for food, farming, pastoral and fisheries systems determined by local producers and users. Food sovereignty prioritises local and national economies and markets and empowers peasant and family farmerdriven agriculture, artisanal fishing, pastoralist-led grazing, and food production, distribution and consumption based on environmental, social and economic sustainability.

Food sovereignty therefore charts a radically different path to adequate nutrition, one based on locally produced and biodiverse foods that build on traditional varieties and knowledge, native seeds and local breeds, and local markets. It also leads to local food processing and value addition with significant impact in terms of local value chains, entrepreneurship, employment and local market development. It promotes a new healthy nexus between rural and urban areas and a stronger bond between consumers and local producers. It also fosters the sustainable use of resources and greater climate resilience.

\section{Complex and multidimensional root causes of malnutrition in all its forms}

Food sovereignty is a necessary condition to ensure adequate nutrition but may not be a sufficient one. As stated by the 'CSO Vision Statement on Nutrition' produced by public interest civil society organizations that have actively engaged in the preparatory process of ICN $2,{ }^{3}$ 'the root causes and factors leading to malnutrition in all its forms are many, complex and multidimensional and cannot be separated from their broader social, political and economic determinants'.
Tackling the root cause of undernourishment, stunting, wasting, micronutrient deficiencies, overweight and obesity, and diet-related non-communicable diseases, requires coherent engagement with a wide-variety of different domains. Building community-based capacity to address acute child malnutrition, strengthening the conditions to make full use of the 1,000-day window of opportunity from a woman's pregnancy to her child's second birthday, removing barriers to the protection, promotion and support of optimal breastfeeding, and fostering proper education to address the changing nutritional needs over the lifecycle, are only some of many interconnected and mutually reinforcing spaces for policy and action.

This evidence highlights once again how nutrition is deeply embedded in many domains of life and how the human right to adequate food and nutrition can only be realized if women's, peasants', and workers' rights, sexual and reproductive rights as well as the right to health, safe water and sanitation, among others, are fulfilled.

\section{The public policy space needs to respond to right-holders rather than stakeholders}

The centrality of the right to adequate food and nutrition, women's rights and all other related rights, involves profound consequences on the nature of the food and nutrition policy space.

First, it means that it is a public policy space that aims to protect, promote and fulfil human rights, where the State as duty-bearer needs to meaningfully respond to right-holders rather than stakeholders. Such space should therefore be protected from undue corporate influence and promote direct participation of those most affected by food insecurity and malnutrition in all its forms. This shades significant shadows on the role of the recently so-fashionable multistakeholder partnerships, as they can actually provide potentially mechanisms for corporate encroachment on key policy decisions pertaining to public health, food and nutrition.

Second, there is a need to protect and enhance the national policy space against the increasing influence of international agreements that limit national sovereignty and impose an unacceptable 
normative hierarchy of trade and finance over human rights. As stated in the earlier referred CSO Vision Statement, '[...] an informative example in this regard is the inclusion of investor-state-disputesettlement (ISDS) mechanisms in free trade agreements (FTAs), which allow private investors to bypass domestic legal systems and sue governments for potential losses in profit caused inter alia by enactment of public health regulation [...], and deter countries from engaging in national food and nutrition security programmes. Such mechanisms severely undermine States' sovereign rights and obligations to regulate in the public interest'.

Lastly, it is imperative to build coherence among different policy domains as the food and nutrition policy space is intimately connected with and dependent on consistent policies and programmes in public health, women's empowerment, agricultural development, environment and commerce, among others. It is therefore imperative to reverse the above-mentioned normative hierarchy to ensure that rights-based policies rule over interest-based ones within trade, finance and other economic domains.

\section{The global governance of food and nutrition: merits and demerits of ICN2}

In an increasingly globalized world, it is very difficult to protect the national policy space without a 'legitimate, coherent, accountable and participatory [global] governance mechanism, safeguarded against undue corporate influence'. ${ }^{2}$ In this respect, ICN2, as an intergovernmental process, exposed merits and demerits.

Public interest civil society organizations welcomed the conclusions of the ICN2 negotiations, against the significant risk of failure, but considered the outcome as inadequate to confront the scale of the malnutrition challenge. The Rome Declaration and Framework for Action ${ }^{4}$ are based on an incomplete and superficial analysis of the root causes of malnutrition, leaving out critical dimensions such as the violations of women's rights, the role of 'commerciogenic' malnutrition and the abusive practices of the corporate sector. Similarly, the implications of trade rules, the 132 impact of land and ocean grabbing and the urgency of climate change are glanced over in a rather apolitical manner. As stated in the CSO Vision Statement, '[...] the negotiations exposed profound differences among governments in both the understanding of the problems and the possible ways forward, casting serious doubts on the real extent and depth of the common political foundation and commitment behind the formal deliberations'. The perfect example of this is the absence of any strong re-affirmation of the centrality of the human right to adequate food and nutrition, and other related rights. While including some valuable recommendations, the Framework for Action does not contain any binding resolutions, places poor emphasis on the necessary policy re-orientation to challenge the hegemony of the current unsustainable food system and does not provide any prominent support to alternatives based on food sovereignty, agro-ecology and biodiversity.

Despite all this, the ICN2 outcome is an important step in ensuring that the global governance of nutrition rests firmly within the government-led normative and regulatory frameworks provided by FAO and WHO. Furthermore, there is a strong call by public interest civil society organizations, social movements and a growing number of Member States, to recognize the UN Committee on World Food Security (CFS) as the critical space where policy coherence for food security and nutrition needs to be established. Indeed, the several attempts by some Member States to provoke stalemates in the negotiations correlate well with the rumours related to the possible establishment of a new nutrition coordination mechanism within the UN system removed from the direct accountability to Member States and under the direct influence on strong donors. The ICN outcome, albeit weak, prevents the establishment of a potentially dangerous vacuum of governance and opens a new path to strengthen the indivisible policy nexus between food, nutrition and health.

\section{Pre-ICN2 Civil Society Forum: the confluence of rivers and the emergence of a new power}

The ICN2 process generated another important outcome. Over the past year, an increasing number 


\section{Prato and Bullard: Editorial}

of public benefit organizations came together to dialogue and coordinate their positions and advocacy strategies. After the initial polyphony of input and statements, since September 2014 civil society spoke with a consensus voice and provided substantive collective input to the negotiation process, despite the very limited, if not completely insignificant, spaces for engagement.

This process culminated into a two-day Civil Society Forum with 200 participants. The Forum preceded ICN2 and witnessed the confluence of many rivers: public benefit civil society organizations working in health, food and nutrition as well as broader development policy issues met with representatives of all main constituencies of social movements. After intense discussions and fruitful dialogue, ${ }^{5}$ a powerful declaration was democratically developed and presented to the closing plenary of ICN2 as a part of its formal outcomes. It has been included as an annex to this editorial as it marks the emergence of new powerful coalition that will advance the agenda to address malnutrition in all its forms, promote a people-centred and convivial alternative to the current hegemonic form of globalization and foster a democratic and accountable global governance of nutrition.

\section{This journal}

Many of the questions raised in this editorial are explored in greater depth in the articles published in this Journal. Ranging from a panoramic overview of the nutrition debates to close up analysis of local practices and alternatives, the authors speak from diverse experiences and perspectives, but all agree that nutrition is a culturally, politically, economically and ecologically embedded challenge.

In the Upfront section, the authors provide strong frameworks for analysing the roots of the nutrition crisis and provide paradigmatic alternatives - in particular human rights in all its expressions and food sovereignty - for overcoming the structural, political and economic causes of malnutrition.

Jomo Kwame Sundaram outlines three priority areas for public intervention against malnutrition: social protection, raising the net incomes of smallscale agricultural producers and using special instruments to address nutritional deficiencies in mothers and children under five years of age. He underlines the importance of public policy and the role of government intervention. Addressing the institutional questions from a rather different perspective, Christina Sathyamala traces the history of the League of Nations Health Organisation - the precursor to the WHO - where the 'marriage' between nutrition and commerce was brokered and how this continues to shape the institutional responses to hunger and malnutrition.

Flavio Valente and Olivier De Schutter approach food and nutrition from a rights perspective. De Schutter argues that although the right to food and nutrition security is a useful framework, ultimately, it is by deepening democracy and empowering citizens that nutrition for all can be achieved. Similarly, Valente emphasizes a human rights approach, particularly the indivisibility of rights and argues that the promotion of women's rights in particular is fundamental to ensure nutritional well-being and human dignity.

Throughout the journal, many authors underscore food sovereignty as a fundamental paradigmatic shift to address malnutrition in all its forms, but also to support the livelihoods and well-being of peasant farmers, to restore biodiversity and to challenge the agro-industrial complex. La Via Campesina has been at the forefront of the campaign and movement for food sovereignty and the interview with Andrea Ferrante shows clearly the connection between food sovereignty, peasant's rights and overcoming the global nutrition challenges.

In the Thematic section, the authors dive deeper into the issues. Nicoletta Dentico explores the relationship between nutrition, health and power, Debbie Barker and Elenita Daño examine the limitations of and the interests behind genetic engineering and bio-fortification as a response to nutrition, while Alice Martin-Prével shows how the World Bank's 'Benchmarking the Business of Agriculture' is opening the field for agribusiness and landgrabbing.

Land is also the central concern of Zoe Brent, Christina Schiavoni and Alberto Alonso-Fradejas who explore the intimate link between land and nutrition, highlighting the fact that land is rarely 


\section{Development 57(2): Editorial}

factored into the official discourse and response to nutrition.

In the Dialogue section, the authors bring together policy and practice, each showing how different approaches on the ground can contribute to strengthening food and nutrition security in ways that are long term, ecological and locally controlled. Michael Krawinkel shows the intimate connection between culture, food and health, and argues that locally produced, indigenous and seasonal foods are the best path to nutrition, not only in terms of physical health but also 'dignity in eating'. In her article about the practical experiences of growing spirulina algae, nettle leaves and the moringa tree, Marinella Correggia demonstrates the vital link between environment, nutrition, indigenous knowledge and the strengthening of local economies.

Tim Lang puts forward the notion of "sustainable diets' - focussing on environmentally low impact, culturally appropriate and economically viable food production - as a simple yet powerful tool for changing public policy and transforming food systems. Cinzia Scaffidi explains how the Slow Food Movement - which describes itself as a 'movement in defence of pleasure' - has developed a dense approach to food and agriculture that integrates all dimensions, from production to market, from traditional culture to biotechnologies and from education to social justice.

Finally, starting from the 'local' and looking out to the larger context, Vandana Shiva from India, Aruna Uprety from Nepal, and Xaviera Cabada and Alejandro Calvillo from Mexico, provide insights into the complex dynamics of culture, tradition, gender, science, politics, policy and power. Shiva shows how genetically engineered food fortification threatens to undermine local varieties and traditional knowledge while exposing the links to global research agendas and corporate interests. Uprety draws on her long experience as a medical doctor in Nepal to show how gender and culture frequently undermine girl's and women's health and nutrition. She also emphasizes the importance of education and training to empower people to understand the nutritional value of local foods and to re-discover practices that have been displaced by processed foods.

The case of Mexico shows how the recent transformation of traditional food production and consumption in the interests of agri-business has resulted in a nutritional crisis of epidemic proportions. Cabada and Calvillo underscore the importance of civil action and engagement as well as government regulation to stop and reverse this downward trajectory.

\section{Notes}

1 The Statement by Social Movements on Nutrition (see Last Word in this issue) was developed during the pre-ICN2 meeting of social movements that took place on 16 November 2014 in Rome, Italy. This meeting preceded the preICN2 Civil Society Forum where the statement was presented as an input by social movements to the civil society discussion.

2 Declaration of Nyéléni adopted on 27 February 2007 by about 500 delegates from more than 80 countries at the Forum for Food Sovereignty, which was held in Sélingué, Mali (http://nyeleni.org/spip.php?article290).

3 CSO Vision Statement on Nutrition (http://www.csm4cfs.org/news/?id=194) prepared by public interest civil society organizations that have actively engaged in the preparatory process of ICN2 as an input to the pre-ICN2 CSO Forum.

4 http://www.fao.org/3/a-at641e.pdf.

5 See the 'Civil Society Declaration on Nutrition' on page 135 in this issue. 